\title{
Erratum to: High-yield production of manganese peroxidase, lignin peroxidase, and versatile peroxidase in Phanerochaete chrysosporium
}

\author{
Nancy Coconi-Linares • Denis Magaña-Ortíz • Doralinda A. Guzmán-Ortiz • \\ Francisco Fernández • Achim M. Loske • Miguel A. Gómez-Lim
}

Published online: 19 October 2014

(C) Springer-Verlag Berlin Heidelberg 2014

\section{Erratum to: Appl Microbiol Biotechnol DOI 10.1007/s00253-014-6105-9}

The original publication of this paper contains two errors.

1) Figure 1d was incorrectly presented. The corrected Figure is attached.
2) The caption of Table 2 was incorrectly presented. The correct caption should be:

Table 2 Comparison of steady-state kinetic constants of recombinant VPL2 (PcT1 transformant) and native VPL2, using three representative substrates a

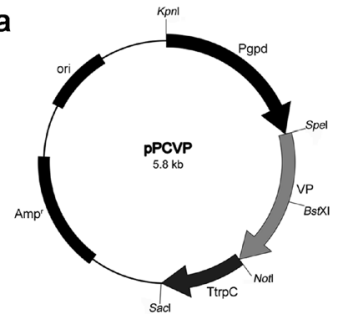

C

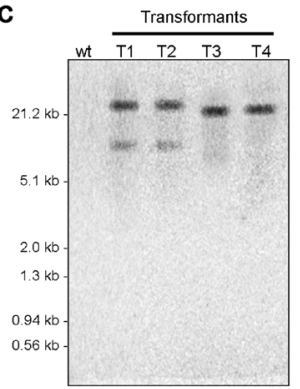

b

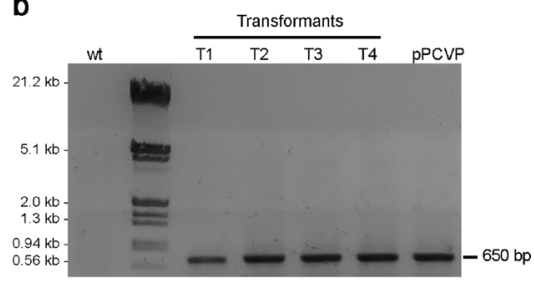

d

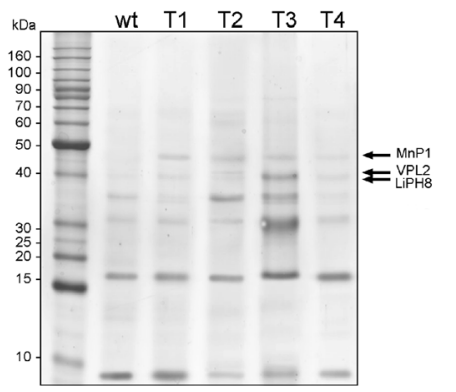

The online version of the original article can be found at http://dx.doi.org/ 10.1007/s00253-014-6105-9.

N. Coconi-Linares $\cdot$ D. Magaña-Ortíz $\cdot$ D. A. Guzmán-Ortiz •

M. A. Gómez-Lim $(\square)$

Centro de Investigación y de Estudios Avanzados del IPN, Unidad

Irapuato, Km. 9.6 Carretera Irapuato-León, 36821 Irapuato, Gto,

Mexico

e-mail: mgomez@ira.cinvestav.mx

F. Fernández $\cdot$ A. M. Loske

Centro de Física Aplicada y Tecnología Avanzada, Universidad

Nacional Autónoma deMéxico, A.P. 1-1010, 76000 Querétaro, Qro,

Mexico 